\title{
Value at Risk and Market Risk: Case of the Regional Securities Exchange
}

\author{
Mouhamadou Saliou Diallo \\ ${ }^{1}$ Faculté des Sciences Economiques et de Gestion, Université Cheikh Anta Diop, Dakar, Sénégal \\ Correspondence: Mouhamadou Saliou Diallo, Faculté des Sciences Economiques et de Gestion, Université Cheikh Anta \\ Diop, Dakar, Sénégal.
}

Received: August 31, 2020

Accepted: September 24, 2020

Available online: September 30, 2020

doi:10.11114/aef.v7i6.4987

URL: https://doi.org/10.11114/aef.v7i6.4987

\begin{abstract}
The study of the BRVM market risk using the VaR method is a determining factor in assessing the performance of our equity portfolio composed of the BRVM composite index and the BRVM10 index. It has enabled us, with the help of Basel regulations, to use backtesting to determine the minimum amount of capital that an investor must hold per day to protect against risk. The kupiec test enables us to determine the reliability of VaR calculated at different confidence levels. The result of our study confirms, using the extreme VaR method, the robustness of our threshold-based portfolio risk management approach. It also confirms the problem of market attractiveness during times of financial crisis.
\end{abstract}

Keywords: value at risk, value at risk extreme, backtesting, regulatory capital

\section{Introduction}

In the 1950s and 1960s, researchers such as (Markowitz, Lintner, Treynor, Sharpe, and Mossin) undertook fundamental work on risk. This led to modern portfolio choice theory based on the CAPM (Capital Asset Pricing Model).

The Black-Scholes model (1973) is probably the most popular. Its authors were the first to propose an explicit pricing formula for a derivative product, that of an option. Later, (Merton, 1974) extended it and published a model based on the probability of default. This model postulates that default occurs when the value of a company's assets falls below the value of its debt.

The growth of the options market increased rapidly after the Chicago Board Options Exchange standardized contracts and developed secondary markets, which are necessary to generate the liquidity required for efficient market functioning (Smith, Smithson and Wakeman, 1990). During the 1980s and 1990s, the introduction of these hedging products made market participants more aware of the risks they were incurring in their day-to-day management and investment activities (Hull and White, 2017).

At the end of the 1980s, high market volatility prompted major US investment banks to set up risk management departments (Field, 2003). JP Morgan developed the two best-known internal risk management models, RiskMetrics for market risk in 1992 and CreditMetrics for credit risk in 1997. These models put into practice the desire to measure risks in portfolio form, taking into account their dependencies, and to use Value at Risk to quantify the aggregate risk of portfolios. Indeed, the publication of the RiskMetrics model has enabled the Value-at-Risk (VaR) risk measure to be widely disseminated, both by professionals and academics. This was imported from insurers who used a similar risk measure to calculate their maximum annual losses (MPY, Maximum Probable Yearly Aggregate Loss). VaR is the maximum value that a portfolio or company can lose over a given period of time at a chosen level of confidence. This measure also provides a measure of the optimal capital required to protect companies or portfolios from anticipated and unanticipated losses (Fermanian and Scaillet, 2003). To this end, the Basel Accords were created to address the coverage of financial risk. These agreements are based on a principle initially setting a minimum capital ratio for the bank to protect itself against market risk.

The first Basel agreement in 1988 imposed a new regulatory vision on credit risk. However, the pressure on the financial markets and the significant growth in market risk led to an amendment to Basel I as early as 1996. Reflections on a second agreement were carried out in 2001 on the initiative of the banks, which demanded more specific rules on market risk. Basel II was adopted by the central banks in 2004 and introduced in the various countries concerned at the end of 2006. Following the subprime crisis, an amendment to the Basel II agreements was introduced in 2009. It was incorporated into the Basel III agreements, approved at the G20 summit in Seoul (September 2010). 
The objective of this study is therefore to assess the level of short-term risk on the Regional Stock Exchange (BRVM) and to offer the market investor the possibility of mobilising the minimum capital required to protect his investment against bad conditions or losses associated with price variations.

In this paper, we do not consider the risk of default, i.e. the probability of counterparty default. Only the risks associated with changes in the price or yield of shares listed on the BRVM are considered. But if we are particularly interested in the maximum downside risk to which we are exposed, the so-called Value at Risk, VaR for short, may be a more appropriate instrument. This model has put into practice the desire to measure risks in portfolio form, taking into account their dependencies, and to use Value at Risk to quantify the aggregate risk of portfolios.

The rest of the document is organised as follows. In section 2, we present VaR. Section 3 discusses the regulation of the Basel Capital Accord. Section 4 is devoted to the model and type of VaR that we will implement in this work. In section 5 we analyse the performance of the portfolio. Backtesting and the Kupiec test are discussed and finally, section 6 is devoted to the conclusion.

\section{Value at Risk (VaR)}

\subsection{Background}

The increased volatility observed in the markets over the last few decades, the collapse of the fixed exchange rate system and the advance of new methods such as the adoption of the Black and Scholes model (1973) have led to a "revolution in the practice of risk management". Short-term capital flows are increasing; "financial innovation" is increasing the complexity of financial transactions and instruments; and the power of financial institutions and large firms is growing (Duménil and Levy, 2002). Stock market crashes such as the October 1987 and autumn 2008 stock market crashes, financial crises such as the Barings Bank financial disasters, the subprime crisis in the summer of 2007, etc. have all highlighted the need to improve internal risk management tools. (Dowd, 1998, Jorion, 2001).

On the theoretical level, (Markowitz, 1952) developed the theory of portfolio management to measure portfolio risk. This work was continued by (Sharpe, 1963), (Lintner, 1965) and (Moslin, 1969) who approached the study of risk management with the CAPM model.

On the technical level, financial institutions began to develop their own risk management models in the 1970s and 1980s. However, it was with J.P Morgan in his 1994 publication of RiskMetrics ${ }^{1}$ that the VaR technique flourished (Dowd, 1998; Jorion, 2001). During this process, regulators also became interested in VaR. The 1996 Basel Capital Accord played an important role, as it allowed banks to use their internal VaR models to calculate their regulatory capital requirements, (Linsmeier and Pearson, 1996). Since then, VaR has been one of the most widely used techniques for measuring market risk.

\subsection{The Foundation of VaR}

There are different types of risks that companies may face. These are credit risks, market risks, liquidity risks, operational risks, legal risks, etc. This study will focus on market risk, which is subdivided into four categories: interest rate risks, share price risks, exchange rate risks and raw material price risks (Dowd, 1998).

VaR was originally developed to measure market risk. It allows the investor, by setting a confidence level $(\alpha \%)$, to know the maximum loss $(\sigma)$ that he should bear during a given period $(\mathrm{t})$ on his initial portfolio investment $(\mathrm{W})$ (Jorion, 2001). The VaR quantifies the risk that the investor could bear in a situation of declining portfolio performance. It is measured by the following equation:

$$
\operatorname{VaR}_{\alpha}=\alpha * \sigma * W
$$

The choice of time horizon depends on the use of VaR. A trader calculates profit and loss every day. His position is usually liquid and actively managed. For internal use, it therefore makes sense to calculate VaR over a time horizon of one business day. If the $\mathrm{VaR}$ is unacceptable, the portfolio can be readjusted relatively quickly. On the other hand, a VaR over a longer time horizon would make little sense, given the variations in the composition of the portfolio.

A number of factors influence the choice of the VaR confidence level. Consider a bank that wishes to maintain an $\mathrm{AA}^{2}$ credit rating. This bank can choose a $99.7 \%$ confidence level and a time horizon of one year for its internal risk management system.

\footnotetext{
${ }^{1}$ RiskMetrics was originally a web-based service to promote VaR as a risk management method. The service provided free data to calculate market risk. Later RiskMetrics became an independent consulting and software company. www.riskmetrics.com

${ }^{2}$ Companies rated AA have a one-year probability of default of $0.03 \%$.
} 


\subsection{VaR Calculation Methods}

We have two approaches to calculating VaR.

\subsubsection{Parametric Approach}

This method determines the VaR of a portfolio of assets based on an explicit parametric distribution law of gains/losses.

If $P_{T}-P_{0}$ is distributed according to a distribution law whose distribution function is known and denoted $\mathrm{F}$, then $p\left[P_{T}-P_{0} \leq \operatorname{VaR}_{\alpha}\right]=1-\alpha$ becomes $F\left(\operatorname{VaR}_{\alpha}\right)=1-\alpha$ or $\operatorname{VaR}_{\alpha}=F^{-1}(1-\alpha)$.

We therefore seek to determine explicitly the parametric distribution law of the profit and loss function. We will generally decompose this function according to its exposure to various risk factors using, for example, methods of approximation by differentiation (analysis by the sensitivity of bonds, or by the delta of options, which is the derivative in relation to the price of the underlying asset), and on these factors we will make distributional assumptions. After estimating the different parameters on the historical data, the VaR will be determined from the decomposition chosen at the outset.

This method consists of five distinct steps:

1. A model of the evolution of the gains/losses of the portfolio is determined according to the different risk factors (which may be the returns of the financial assets making up the portfolio).

2. Relevant parametric laws are chosen which correspond to the distributional qualities of the risk factors.

3. The parameters of these laws are estimated on the basis of past data using traditional statistical methods (methods of moments or maximum likelihood).

4. The probability law of profit and loss is determined from the chosen model.

5. The quantile associated with the confidence threshold is calculated.

The most generally used probability law is the normal law, whose remarkable properties allow a significant simplification of the calculations. A common example of a parametric method is given by Jorion (2001) under the name of the delta-normal method: one seeks to approximate all portfolio positions by its linear exposure to the various risk factors. The undeniable simplicity of the method comes at the price of inaccuracies linked, on the one hand, to the use of the normal distribution (which records poor precision in practice for the extremes of the asset distribution) and, on the other hand, to the poor quality of a linear approximation, particularly for instruments such as options.

Parametric methods obviously cannot be reduced to the normal distribution. Student's law may thus seem better suited to empirical profitability observations; moreover, it remains very simple, characterized by a position parameter (mean), a scale parameter (analogous to variance) and a parameter of degrees of freedom (which controls the thickness of the tails). On the other hand, the empirical descriptive potential of the alternative laws goes, in most cases, hand in hand with a considerable increase in the calculation of VaR, especially in the case of large portfolios where one loses the very useful property of distributional stability by aggregation (a portfolio of normal securities remains normal). In such cases, it is no longer possible to reason by risk factor decomposition since the final aggregation is made more complicated.

The significant advantage of this method is the simplicity of its implementation. Moreover, for the user, it is easier to work with processes in which one masters all the springs, both theoretical and technical. And having a tool whose limits are known, makes it all the more relevant to use.

The main flaw of the method is that it requires a knowledge of the distribution law of risk factors, which is rarely the case. This can lead, if necessary, to the use of unlikely hypotheses such as the use of the normal law despite the empirical evidence accumulating over the years against this postulate. Moreover, even if the method allows the use of conditional laws, in practice the very binding assumption of stationarity is used. Past data appear as a sample of random draws of the past law, which practice regularly refutes.

\subsubsection{Historical Simulation}

This method is the simplest to implement. Unlike the parametric method, it does not make assumptions about returns in terms of distribution or independence. It is based on the stationarity of variations in the various risk factors for the chosen horizon, and today replicates past fluctuations.

As with the parametric method, four distinct steps can be defined:

1. Past fluctuations in the portfolio's return are calculated from a history of the valuations of the securities in the portfolio.

2. We adapt the past performance history to the current valuation of the portfolio to simulate today future gains and losses. 
3. Profits or losses are calculated and ranked in ascending order and a histogram of the distribution is created.

4. The desired quantile associated with these simulations is determined.

The theoretical disadvantage is that this method is based on the assumption of stationarity, which implies that the future behaves like the past. However, this is rarely encountered in reality. Indeed, financial series are characterised by volatility clusters (grouping of periods of high volatility followed by periods of low volatility) and the method cannot anticipate the future period for the chosen time horizon. This can thus lead to estimates of VaR that are lower than the actual value. In addition, the results of the method will be dependent on the most unfavourable losses in the past, whereas adjusting a parametric distribution on the observations would smooth out the historical information.

From an operational point of view, the method requires a large amount of data and requires the company implementing it to possess, or purchase from specialized companies, a consistent and reliable data source.

However, we have seen that the parametric model over-used the assumption of unproven normality of returns. The historical method is not dedicated to a particular statistical distribution of returns and does not require any model assumption. It may therefore be able to account more accurately for particular distributional phenomena such as long tail distributions, which are difficult to explain in other models.

Moreover, the implementation of this method is very simple (even if it can sometimes be a bit cumbersome when there are too many data).

\subsubsection{Monte Carlo simulation}

This method replicates the paths of the two previous methods. This time it will involve selecting fluctuation models for the different risk factors and simulating a large number of trajectories. Future simulations are created whereas they are provided in the past in the historical method.

Six distinct steps can be defined:

1. A model of the evolution of the portfolio gains/losses is determined according to the various risk factors.

2. Parametric evolution models are chosen for each risk factor.

3. The parameters of these models are estimated from historical data.

4. A large number of gains/losses are simulated.

5. These gains/losses are ranked in ascending order and a histogram of the distribution is created.

6. Determine the desired quantile associated with these simulations.

This method is often considered the most powerful, allowing for broad coverage of risk factors and risk exposures, including non-linear derivative exposures, (Dowd, 1998). Its flexibility allows for variations in volatility and therefore thick tails in the distribution of returns. Finally, the ability to generate a large number of gains and losses makes it possible to easily study and calculate other characteristics such as the expectation of extreme losses, which the parametric method does not easily allow.

The pitfalls of this method are numerous and are commensurate with its advantages. The first pitfall is the model risk linked to the selection of risk factor fluctuation models and their calibration. They may in fact intrinsically underestimate portfolio losses.

Secondly, implementation can be tricky, depending on the complexity of the models chosen and the number of risk factors defined. This requires in-house expertise familiar with simulation methods for the most complex models.

Finally, all of this requires high IT resource requirements when it comes to simulating millions of sophisticated model trajectories. The calculations can thus require a long computing time to the detriment of the desirable flexibility of such a tool.

\subsection{VaR Limits}

Some methodological limitations regarding VaR can be noted. For example, in a crisis situation, VaR does not reflect the correct value of risk. Therefore, it is important to look at values that go beyond the confidence level that investors set for quantifying risk. The stress testing process is proving to be extremely useful in managing the response to different crises such as the COVID pandemic19 .

Moreover, portfolios with the same $\mathrm{VaR}$ can also provide risk information that is not necessarily of the same nature (Tsai, 2004). VaR should then be analysed. The calculation of VaR is based, through the variance/covariance matrix, on the correlations between assets; the stability of these correlations is not always verified, especially beyond the confidence threshold; this is one of the reasons why it is necessary, in addition to $\mathrm{VaR}$, to evaluate crisis scenarios (stress tests) that quantify possible losses during extreme events that may be atypical. 
Conventional VaR calculations do not adequately take into account the risks of a change in the liquidity of certain markets, whereas a drying up of this liquidity during a period of stress amplifies the risk of losses.

The variety of methods used to calculate VaR figures allows a good adaptation to the specific products whose risk is to be managed. However, it has the disadvantage of making it difficult to interpret a VaR figure or to make comparisons between several VaR figures: the results of the calculations may differ significantly depending on the method used; the possible parameters for the same method are often numerous and may have a significant impact on the results; and lastly, the more global the VaR figure, the less information it provides on the nature and relative weight of the various risk factors at work.

In addition, $\mathrm{VaR}$ does not consider certain related issues such as the return obtained on positions, and therefore the risks taken. It is therefore not impossible that an increase in VaR may in fact be accompanied by an improvement in the risk/return ratio if ex post profitability increases faster than $\mathrm{VaR}$ (which is an ex ante measure of risk).

In this study, we will take into account the recommendations of (Tsai, 2004). In other words, we use the VaR technique based on extreme value theory in the context of the BRVM. Second, the Basel regulatory framework is necessary to set the minimum amount of capital to be held by the investor to guard against market risk.

\section{The Regulation of the Basel Agreements}

Prior to 1988, the regulation of bank capital in many countries consisted of establishing a minimum level of the ratio of capital to total assets. However, the definitions of capital and capital ratios and the ratios themselves differed from country to country.

Another difficulty was the complexity of the transactions carried out by banks. The very rapid growth of derivative markets, such as interest rate swaps and currency options, increased the credit risk of banks.

The 1988 BRI agreement represented the first attempt to establish international standards for adequate risk-adjusted capitalization. This agreement defined two minimum standards of capital requirements. The first was similar to the pre-1988 one and required banks to have an asset-to-capital adequacy ratio of less than 20 . The second introduced the ratio subsequently known as the Cooke ${ }^{3}$ ratio. The ratio of shareholders' equity to weighted assets must be equal to or greater than $8 \%$ with a minimum of $4 \%$ for Tier $1^{4}$. However, this agreement has a number of weaknesses. Indeed, all loans granted to companies have a risk weighting of $100 \%$ and therefore require the same amount of capital. A loan to an AA rated company is treated in the same way as a loan to a B rated company. In addition, no default correlation model is offered by Basel I.

In June 1999, the Basel Committee proposed new rules, known as Basel II, which were revised in January 2001 and April 2003. The new rules are divided into three pillars:

1. Minimum capital requirement ;

2. Supervisory review process ;

3. market discipline.

Following the credit crisis, changes to the rules for calculating capital for market risk were proposed. They are known as Basel 2.5 and were implemented on 31 December $2011^{5}$. The three main changes are as follows :

1. the calculation of an extreme VaR (stressed VaR);

2. a new charge for incremental risk ;

3. a measure of overall risk taking into account credit correlation.

The effect of these measures is to significantly increase the capital for market risk that banks must now hold.

Following the credit crisis of 2007-2009, the Basel Committee decided that a far-reaching reform of the Basel II Accords was necessary. Basel 2.5 increased the capital required for market risk, but it was also necessary to increase it for credit risk. In addition, it became necessary to redefine the concepts of regulatory capital and to establish liquidity risk regulation. The new agreement consists of six parts:

1. Definition of capital requirements ;

\footnotetext{
${ }^{3}$ Named after Peter Cooke of the Bank of England.

${ }^{4}$ Tier 1 represents the portion of equity capital considered to be the strongest. It is globally made up of the share capital, the share of the profit placed in reserves, ordinary shares and minority interests.

${ }^{5}$ See Basel committee on Bank Supervision, Revisions to the Basel II Market Risk Framework, febuary 2011
} 
2. capital conservation cushion ;

3. counter-cyclical cushion ;

4. leverage ratio ;

5. liquidity risk ;

6. counterparty credit risk .

\subsection{The Internal Model Approach}

The Basel Committee presented a regulatory innovation in April 1995. This is the internal model approach (Jorion, 2001). For the first time, banks would be allowed to use their own risk management models to determine their VaR and, with them, their capital requirements. This capital requirement follows simply by multiplying the VaR by a complementary factor. This complementary factor, sometimes referred to as the hysteria factor, can vary between three and four, depending on the accuracy of the bank's model in the past ${ }^{6}$. The hysteria factor is intended to provide additional protection against much less stable environments than historical data would suggest. The capital-investment requirement depends on the outcome of the back testing or ex post VaR model (Cambell, 2005). The required market risk capital is formally defined as :

$$
C R M_{t}=\max \left[\operatorname{VaR}_{t}(0,01), S_{t} \frac{1}{60} \sum_{i=0}^{59} \operatorname{VaR}_{t-1}(0,01)\right]+c
$$

Backtesting involves testing the performance of VaR estimates on past data. Suppose we have developed a procedure for calculating VaR at the $99 \%$ overnight threshold. Backtesting consists in checking the number of times the daily loss has actually exceeded the VaR. In this context, the days on which the daily loss exceeds the VaR are called exceptions. If these exceptions represent $1 \%$ of the days, the VaR calculation methodology can be considered reliable. On the other hand, if they represent $7 \%$ of the days, the calculation is not reliable and probably underestimates VaR and regulatory capital. Symmetrically, if the exceptions represent, for example, $0.3 \%$ of the days, then VaR is overestimated and capital is too high, (Jorion, 2001). A penalty is imposed if a violation of the regulatory threshold results in an additional capital charge. This results in an increase in hysteria, or scale factor. The internal model approach requires a period of one year or 250 trading days.

Of course, this liberal legislation required a number of preconditions. First, the holding period and the level of confiance for VaR calculations had to be fixed. The Committee decided to set the holding period at fixer to 10 trading days. This 10-day period is motivated by the fact that in the event of severe market tensions, such as in October 1987, the markets may encounter liquidity problems. In such cases, unprofitable parts of the portfolio cannot be liquidated in a timely manner. Although banks should report a 10-day VaR, these VaR calculations should be based on daily performance data, which is motivated by the fact that banks change the composition of their portfolio on a daily rather than biweekly basis. In addition, the level of confiance is set at $99 \%$, corresponding to a loss exceeding the VaR once every hundred days, or two to three times a year. The following table sets out the specific sanction guidelines.

Table 1. The relationship between the scaling factor and the counter-test results Area Number of violations Scale factor

\begin{tabular}{ccc}
\hline Zone & Number of violations & Scale Factor \\
\hline \multirow{3}{*}{ Green Zone } & 0 & 3.00 \\
& 1 & 3.00 \\
& 2 & 3.00 \\
& 3 & 3.00 \\
& 4 & 3.00 \\
\hline \multirow{2}{*}{ Yellow Zone } & 5 & 3.40 \\
& 6 & 3.50 \\
& 7 & 3.65 \\
& 8 & 3.75 \\
Red Zone & 9 & 3.85 \\
\hline
\end{tabular}

Table 1 shows that the number of VaR overruns over a period of 250 trading days is capped at 4 . If we are in the green zone, the multiplying factor is 3 , which means that the capital requirement is three times the VaR of the bank's portfolio.

\footnotetext{
${ }^{6}$ In fact, the capital requirement is set at the highest VaR of the previous day and the average VaR of the last 60 business days, multiplied by the addition factor
} 
This scaling factor is gradually increased as we cross the yellow zone, until we reach the red zone where a maximum scaling factor of 4 is imposed. In this case, the bank is obliged to revise its internal risk management model.

In addition to the guidelines on the internal model approach, banks must carry out stress tests, which may subject them to additional capital charges. These stress tests examine the effect of simulated movements in important financial variables on the bank's portfolio. For example, a scenario could be specified in which the equity index would change by plus or minus $10 \%$, or volatilities would change by plus or minus $20 \%$ of their current values. The advantage of this stress test, or scenario analysis, is that it can cover situations that are completely absent from historical data, whereas VaR models are generally and solely based on historical data; stress tests force management to take into account events that it might otherwise ignore. The main disadvantage of scenario analysis is that it is completely subjective; stress tests do not specify the probability of worst-case scenarios. However, scenario analysis can be an important means of exposing weaknesses in a portfolio.

The internal model approach presents banks with a trade-off between core capital requirements and penalty costs. If a bank's internal model underestimates its market risk, the capital base required, which is the VaR, is low, but if the model is too bad, the scaling factor can be set at more than 3. On the other hand, if the VaR estimate resulting from the internal model is relatively high, the bank's overall profit opportunities could be seriously restricted unless it is compensated by a moderate scaling factor. There has been some criticism of the internal model's approach to this trade-off. The difference between the minimum and maximum scaling factor is considered too small. This gives banks an incentive to report a $\mathrm{VaR}$ that is too low, so that profit opportunities are kept high, as the penalty for using a model that undervalues VaR is relatively small. This is why there is a call for higher penalties, see for example (Lucas, 1997 and Vlaar, 1998).

\subsection{The Kupiec Model Approach}

(Kupiec, 1995) proposes a likelihood ratio test to determine the rejection or acceptance of the VaR model. Let $\mathrm{N}$ be the number of times the daily portfolio loss has actually exceeded VaR in a sample of size T. Then, the number of VaR violations follows a binomial distribution $N \sim B(T, p)$, the probability of an exception noted $N / T$ is equal to $\mathrm{p}$ which corresponds to the left tail of the distribution. Thus, the following alternatives are retained :

$$
\begin{aligned}
& H_{0}:{ }^{N} / T=p \\
& H_{a}:{ }^{N} / T \neq p
\end{aligned}
$$

and the likelihood ratio statistic is given by :

$$
L R=2\left[\log \left(\left(\frac{N}{T}\right)^{N}\left(1-\frac{N}{T}\right)^{T-N}\right)-\log p^{N}(1-p)^{T-N}\right]
$$

This distribution follows a law from $\chi^{2}$ with the null hypothesis representing the probability $\mathrm{p}$ that the VaR will be exceeded. The confidence level that allows the construction of the no discharge zones is noted as $100 .(1-\alpha) \%$ and according to the convention, $\alpha$ is set at 0.05 . For the left-tail ends of the distribution, a certain number of probabilities correspond to the no-rejection zones (see table below). Clearly, the lower the probability, the more difficult it is to confirm deviations, especially when the evaluation sample size is small.

Table 2. Non-rejection zones according to the Kupiec ex-post test

\begin{tabular}{ccccc}
\hline & \multicolumn{4}{c}{ Evaluation of the sample size } \\
\cline { 2 - 5 } Probability of left tail & 250 & 500 & 750 & 1000 \\
\hline $5.00 \%$ & $7 \leq N \leq 19$ & $17 \leq N \leq 35$ & $27 \leq N \leq 49$ & $38 \leq N \leq 64$ \\
$1.00 \%$ & $1 \leq N \leq 6$ & $2 \leq N \leq 9$ & $3 \leq N \leq 13$ & $5 \leq N \leq 16$ \\
$0.50 \%$ & $0 \leq N \leq 4$ & $1 \leq N \leq 6$ & $1 \leq N \leq 8$ & $2 \leq N \leq 9$ \\
$0.10 \%$ & $0 \leq N \leq 1$ & $0 \leq N \leq 2$ & $0 \leq N \leq 3$ & $0 \leq N \leq 3$ \\
$0.01 \%$ & $0 \leq N \leq 0$ & $0 \leq N \leq 0$ & $0 \leq N \leq 1$ & $0 \leq N \leq 1$ \\
\hline
\end{tabular}

The size of this test is $5 \%$. 
In contrast to the regulatory approach of the internal model of the Basel Agreement, Kupiec offers a relatively successful bilateral test. Here, high and low default rates lead to a rejection of the model. In particular, overly conservative models are rejected, whereas the Basel Accord guidelines only penalise models that underestimate VaR. For banks, however, it is not only important to know whether their model underestimates VaR, but it is also important to know whether the model is too conservative as this would unnecessarily compromise their profit opportunities. Therefore, for banks, bilateral counter-testing is suitable for model evaluation work. For banking supervisory purposes, only too low VaR calculations are important, and therefore a one-sided test, e.g. a quantile of the binomial distribution, is more appropriate.

For a valuation sample size of 250 trading days and a left-tail probability of $1 \%$, as prescribed by the Basel Committee, the critical value of the one-tailed test is equal to 6 at a 95\% confidence level. This means that a VaR model must be rejected if it makes the $\mathrm{VaR}$ predictions violated more than 5 times in a backtesting period of 250 trading days. The Basel sanctions system is slightly stricter because it begins to impose an additional capital charge for VaR violations above 4. The subsequent gradual increase in the multiplication factor has no clear statistical basis. It merely reflects the Basel Committee's loss function.

Kupiec's Probability of Default Test is hampered by two shortcomings. Firstly, the test is statistically weak with sample sizes in line with the current regulatory framework (one year). This shortcoming has already been recognised by Kupiec itself. Second, the failure probability test only considers the frequency of losses, not the timing of their occurrence. As a result, it may fail to reject a model that produces cluster exceptions. Thus, backtesting of the model should not rely solely on unconditional coverage tests. (Campbell, 2005)

\section{Value-at-Risk Technique Applied to the Regional Stock Exchange}

In this section we assume that the investor has an initial fund of $3000000 \mathrm{XOF}$ and wishes to assess the maximum risk that he should bear at a given level of confidence if he decides to invest in the BRVM market. He then distributes his wealth as follows: $1000000 \mathrm{XOF}$ invested in the BRVM composite portfolio and $2000000 \mathrm{XOF}$ in the BRVM 10 portfolio. He would also like to know the minimum capital to be held to protect himself against this market risk.

Throughout the analysis, a holding period of one day will be used. Various values for the probability level of the left tail of the distribution will be taken into account, ranging from a very conservative level of $0.01 \%$ to at least a conservative $5 \%$. In a context of COVID19 partly corresponding to the period of this study, the stressed VaR model will be estimated using the previous 500-day sample data. We also use the Internal Model of Banks approach to determine the capital required and the Kupiec test approach to validate or reject the VaR.

\subsection{The Data}

We decided to conduct an empirical study to analyse portfolio risk. Indeed, it is very difficult to obtain information on portfolio composition, which changes frequently.

The BRVM was created in 1998 to faithfully represent the WAEMU stock market. It is divided into two indexes: the BRVM composite and the BRVM10. During the period of our study, these indexes underperformed as can be seen in Figure 1 below.

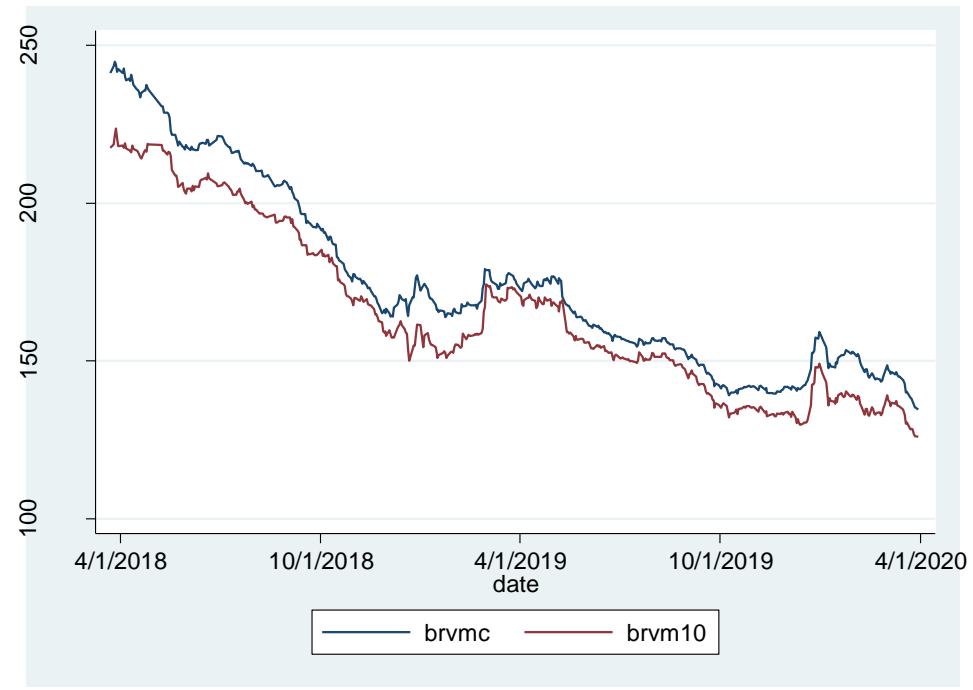

Figure 1. Evolution of BRVM index

Source: author 
Both indexes evolve in a downward trend and their performance is linked to the economic and financial context of the WAEMU zone. The relationship between these indexes offers the same stock market trend. The correlation table (in appendice) confirms this complementarity with a very significant correlation coefficient.

The market capitalisation of the BRVM equity market has considerably decreased between the beginning and the end of the period of this study. Indeed, it stood at XOF 6.786 billion on 23 March 2018 to reach XOF 4.028 billion on 31 March 2020, a drop of 40.64\%. Over the same period, notably on 30 January 2020, the date on which the pandemic was declared by the World Health Organisation (WHO) as a state of health emergency of international scope, the market capitalisation stood at 4.550 billion XOF.

The BRVM is a basket of shares made up of 46 shares distributed throughout the WAEMU sub-region and of different sizes. More than $82 \%$ of the listed companies are Ivorian. Despite this remarkable performance, it has not really established itself in the economic landscape as a space for capital development and mobilisation of financial resources. Firstly, because of its low liquidity. (Hearn and Piesse, 2008) indicate that Mali's average annual order flows represent less than $2 \%$ of the value traded on the regional stock exchange, which is very illiquid. Moreover, this figure is largely dominated by a single individual investor who accounts for more than $90 \%$ of trading in this tiny community of retail investors. Indeed, trading activity and market capitalization are heavily concentrated on the Senegalese telecommunications company SONATEL, which accounts for 53.95 per cent of market value and 46.51 per cent of capitalization (Hearn and Piesse, 2008).

Second, according to (Lavelle, 2001), BRVM concentrates wealth more in the hands of local elites rather than as a redistribution mechanism to enforce high standards of governance through diversified ownership. Yet, designed to spread a maximum of order throughout the West African region, this stock exchange ultimately offers little scope for diversification to institutional investors.

The composition of our portfolio therefore includes 1/3 of the BRVM composite index and 2/3 of the BRVM 10 index. The BRVM Composite includes all listed companies. The BRVM 10 is the index of the "stars" of the stock market since it is composed of 10 of the most active companies on the stock market. These are the most liquid stocks, those which concentrate the most transactions.

In addition, we have a time series covering the period from 23 March 2018 to 31 March 2020 with 500 daily data. During this period the descriptive statistics of the returns of the two portfolios are presented in the following table:

Table 3. Descriptive Statistics of Portfolio Returns

\begin{tabular}{cccccccc}
\hline Variable & Observ. & Skew & Kurto & Min & Max & Mean & SD \\
\hline rdt_brvmc & 500 & -0.468 & 3.567 & -0.035 & 0.028 & 0.001 & 0.007 \\
rdt_brvm10 & 500 & -0.446 & 5.761 & -0.047 & 0.045 & 0.001 & 0.009 \\
\hline
\end{tabular}

Source : author

Table 3 shows that the daily return of the two portfolios is identical and almost zero with a negligible standard deviation. This is an advantage for modelling the daily returns of the portfolio composition as it reduces uncertainty and imprecision on Figleweski (1994) estimates.

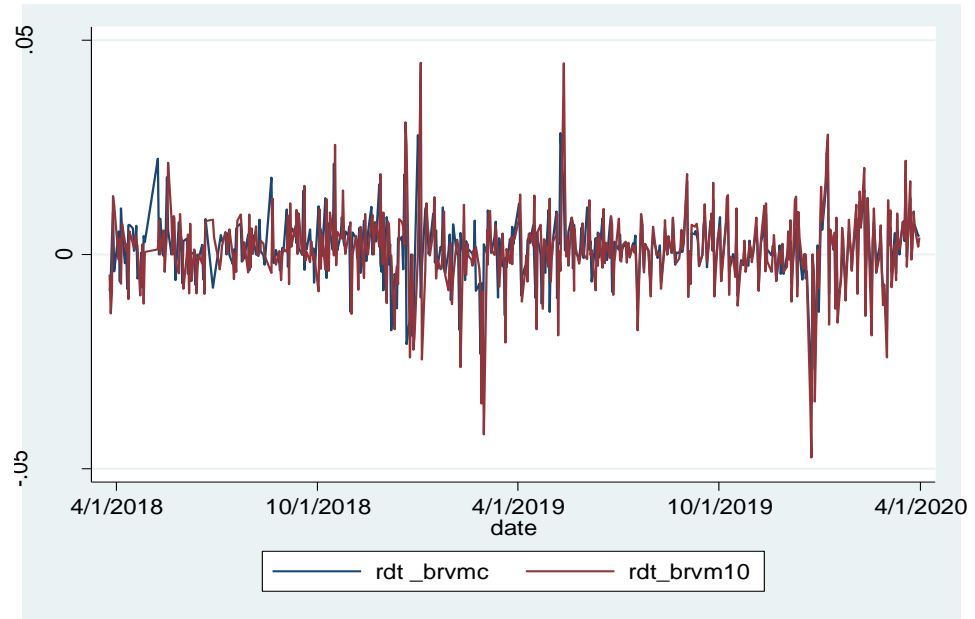

Figure 2. Evolution of portfolio returns

Source : author 
Developments in the BRVMC and BRVM10 portfolios are very similar. Two periods can be identified in the evolution of the portfolios: a stable period that extends until around the end of 2019, and then a period of health crisis. However, over the entire period from 23 March 2018 - 31 March 2020, both portfolios show a zero trend.

It is clear that in times of severe turbulence, such as the case of the COVID19 pandemic a very high VaR measure can be expected. Moreover, the maximum and minimum statistics and the importance of kurtosis tell us about the presence of extreme returns. This is supported by the occasional extreme peaks in Figure 2, which are indicative of the adiposity of the tails of the distribution. Clearly, peaks in distribution can be seen in this figure towards the end of 2019, corresponding to the beginning of the pandemic.

\subsection{Extreme Value Theory}

Gnedenko demonstrated in 1943 the main result of the extreme value theory. It applies to the tail properties of many probability distributions.

Note $F(x)$ the distribution function of a variable $\mathrm{x}$. $\mathrm{u}$ is a value of $\mathrm{x}$ located in the right tail of the distribution. The probability that $\mathrm{x}$ is between $\mathrm{u}$ and $u+y(y>0)$ is $F(u+y)-F(u)$. The probability that $\mathrm{x}$ is greater than $\mathrm{u}$ is $1-F(u) . F_{u}(y)$ is the conditional probability that $\mathrm{x}$ is between $\mathrm{u}$ and $u+y$ where $x>u$. This probability is written :

$$
F_{u}(y)=\frac{F(y+u)-F(u)}{1-F(u)}
$$

Its value defines the right tail of the probability distribution. It is in fact the cumulative probability distribution for a value $\mathrm{x}$ greater than $\mathrm{u}$.

According to Gnedenko's results, for a large number of distributions $\left.(x), F_{u}(y)\right)$ converges to a generalised Pareto distribution as u increases. This distribution is defined by :

$$
G_{\zeta, \beta}(y)=1-\left[1+\zeta \frac{y}{\beta}\right]^{-1 / \zeta}
$$

The two parameters $\zeta$ and $\beta$ are to be estimated. The first is the shape parameter, which determines the thickness of the distribution tail. The second is a scale parameter.

When $\mathrm{x}$ has a normal distribution, $\zeta=0$, the value of $\zeta$ increases with the thickness of the tails and is positive, between 0.1 and 0.4 , for most financial data.

\subsubsection{Estimated from $\zeta$ and $\beta$}

The parameters $\zeta$ and $\beta$ can be estimated by the maximum likelihood method. The density function $g_{\zeta, \beta}(y)$ is obtained by deriving equation (1) with respect to $\mathrm{y}$, and is :

$$
G_{\zeta, \beta}(y)=\frac{1}{\beta}\left(1+\zeta \frac{y}{\beta}\right)^{-1 / \zeta^{-1}}
$$

For example, a u value close to the 95th percentile of the empirical distribution can be used. We sort the observations of $\mathrm{x}$ in descending order to obtain observations such as $x>u$, which we note $x_{i}\left(1 \leq i \leq n_{u}\right)$ and their number $n_{u}$. The likelihood function (under the assumption that $\zeta \neq 0$ is written :

$$
\prod_{i=1}^{n_{u}} \frac{1}{\beta}\left(1+\frac{\zeta\left(x_{i}-u\right)}{\beta}\right)^{-1 / \zeta^{-1}}
$$

Maximising this function means maximising its logarithm :

$$
\sum_{i=1}^{n_{u}} \ln \left[\frac{1}{\beta}\left(1+\frac{\zeta\left(x_{i}-u\right)}{\beta}\right)^{-1 / \zeta^{-1}}\right]
$$

Standard numerical procedures can be used to obtain the values from $\zeta$ and $\beta$ that maximize this equation. 


\subsubsection{Estimation of the Distribution Tail}

$1-G_{\zeta, \beta}(y)$ is the conditional probability of $x>u+y$, where $x>u$. The probability that $x>u$ is $1-F(u)$, and the unconditional probability of $x>u$ is then :

$$
[1-F(u)]\left[1-G_{\zeta, \beta}(x-u)\right]
$$

For a sample of n observations, the estimate of $1-F(u)$ is $n_{u} / n$. In this case the unconditional probability of $x>u$ is :

$$
\operatorname{Prob}(x>u)=\frac{n_{u}}{n}\left[1-G_{\zeta, \beta}(x-u)\right]=\frac{n_{u}}{n}\left(1+\zeta \frac{x-u}{\beta}\right)^{-1 / \zeta}
$$

\subsubsection{Calculation of VaR and Expected Shortfall (Conditional VaR)}

To calculate the VaR at the threshold of q, the equation :

$$
F(\operatorname{VaR})=q
$$

from equation (5) we obtain :

$$
q=1-\frac{n_{u}}{n}\left(1+\zeta \frac{V a R-u}{\beta}\right)^{-1 / \zeta}
$$

such as :

$$
V a R=u+\frac{\beta}{\zeta}\left[\left(\frac{n_{u}}{n}(1-q)\right)^{-\zeta}-1\right]
$$

The Expected Shortfall is given by :

\section{The Performance of the Portfolio}

$$
\text { Expected Shortfall }=\frac{V a R+\beta-\zeta u}{1-\zeta}
$$

In our approach, the performance of an equity portfolio has the meaning of a portfolio management result as well as that of an exceptional result of an equity portfolio management.

\subsection{Descriptive Statistics}

Table 4 below summarises the performance of the portfolio which is composed of $1 / 3$ for the brvmc index and $2 / 3$ for the brvm10 index.

Table 4. Descriptive statistics

\begin{tabular}{cccccccccc}
\hline Variable & Observ & Mean & SD & Min & Max & Skew & Kurto & JB \\
\hline Losses & 500 & -3.486 & 22.001 & -105.610 & 126.856 & 0.645 & 5.632 & 703.848 \\
\hline
\end{tabular}

Source: author

We observe an average gain of 3.486 over the period studied. From this result, it can be argued that it is preferable for a risk-neutral investor to invest in the BRVM market. But this is not sufficient to determine the performance of the portfolio. It is necessary that with this gain, one considers the possible deviations characterised by the deviation - type which gives a large dispersion around the average. Also, it can be seen from the maximum and minimum that the portfolio is exposed to a large loss rather than a large gain. The loss distribution function shown in Figure 3 gives us more information about this exposure to loss, which represents $40 \%$ of the distribution. Asymmetry (skewness) represents a deviation from the symmetrical shape of a distribution (Elisabeta, 2002). Here it presents an asymmetry on the right. The frequencies of occurrence of the losses are spread to the right. We also have, according to kurtosis, a 
leptokurtic distribution of the portfolio, i.e. with a thick distribution tail. This means that the portfolio gives extreme losses with higher than normal frequencies.

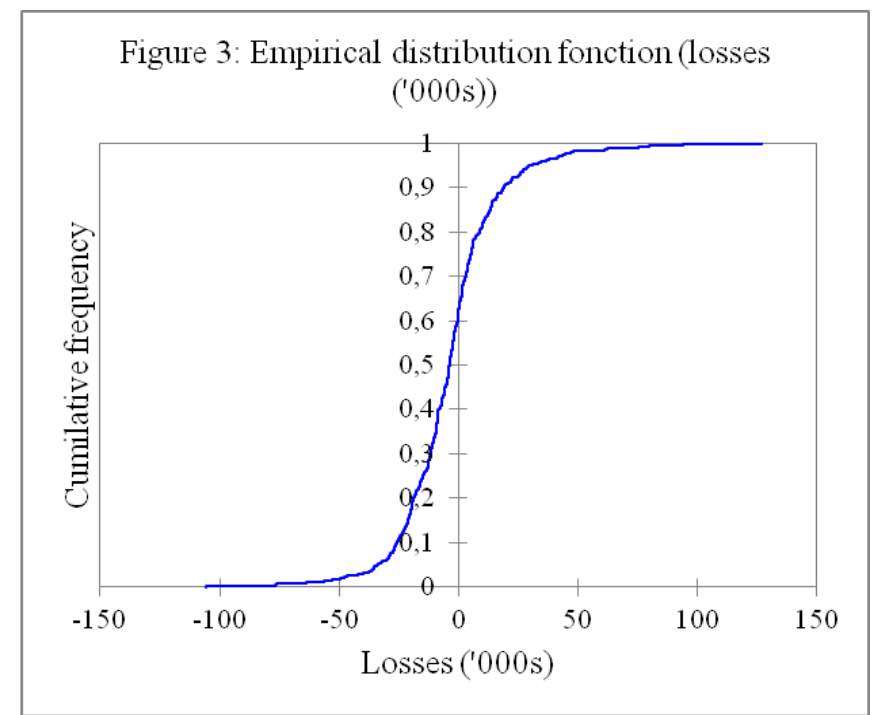

Figure 3. Empirical distribution fonction (Losses’ 000s))

Source: author

A more accurate test of the normality of the distribution was carried out using the Jarque - Bera test, which is above the critical threshold of 5.99. Other tests are done such as the histogram and the Q - Q plot (in appendice) which confirm this abnormality. The portfolio therefore presents some extreme values which may indicate that the distribution of losses is not normal.

\subsection{Portfolio Risk Assessment}

Portfolio risk is assessed using the Extreme VaR calculation technique.

\subsubsection{The Extreme Value Method}

The extreme value method makes it possible to highlight the levels of VaR that the investor could support depending on the level of confidence defined in a crisis situation. Table 5 summarises the following situation:

Table 5. Determination of VaR

\begin{tabular}{cccc}
\hline Confidence level & Observ & VaR & Expected Shortfall \\
\hline $95 \%$ & 500 & 30.000 & 53.781 \\
$99 \%$ & 500 & 68.259 & 92.116 \\
$99.5 \%$ & 500 & 84.774 & 108.664 \\
$99.9 \%$ & 500 & 123.209 & 147.177 \\
$99.99 \%$ & 500 & 178.413 & 202.492 \\
\hline
\end{tabular}

Source: author

This table presents, out of the 500 observations in our sample, the different scenarios depending on whether the investor is risk averse or likes to take risk. When he is conservative, i.e. for a confidence level of $95 \%$, the maximum daily loss of the portfolio is estimated at $30.000 \mathrm{XOF}$ for an initial investment of $3000000 \mathrm{XOF}$. The daily loss is estimated at 123.200 XOF at the $99.9 \%$ threshold if the investor decides to take even more risk on the BRVM market. The probability that the daily loss will exceed $150.000 \mathrm{XOF}$ ( $5 \%$ of the portfolio value) is 0.001 .

The Expected Shortfall provides better incentives in the event of a decline in portfolio value. It is also known as conditional VaR or tail loss and corresponds to the average daily loss at the determined confidence level. 


\subsubsection{Stress Tests}

Stress tests analyse the consequences of extreme variations in market variables. The purpose of these tests is to take into account extreme events that are virtually impossible to observe on the usual probability distributions, but which nevertheless occur from time to time on the market. Parameter estimation gives us the information shown in Table 6 .

Table 6. Parameter estimates

\begin{tabular}{cccccccc}
\hline $\mathrm{u}$ & $\mathrm{b}$ & $\mathrm{z}$ & $\mathrm{n}$ & $\mathrm{n} \_\mathrm{u}$ & $\mathrm{VaR}$ & $\mathrm{ES}$ & Likelihood \\
\hline 30 & 23.733 & 0.002 & 500 & 25 & 123.209 & 147.177 & -104.221 \\
\hline
\end{tabular}

Source: author

Table 6 shows that out of the 500 observations in our sample, 25 scenarios give an estimated daily loss of 30.000 XOF. At the same time, the maximum daily loss borne by the investor is 123.200 at the $99.9 \%$ confidence level. It should be noted that the thicktail distribution (0.002) is of the Fréchet type, which is the case for most financial series. We can therefore deduce at quantiles of extremes to determine maximum daily losses. According to the likelihood ratio, the statistical test of $\chi^{2}$ calculated at one degree of freedom is below the critical value of 3.84 at the $5 \%$ threshold, the model is therefore accepted.

\subsection{Backtesting}

The Basel regulatory framework only applies to banks. Nevertheless, it provides a useful exercise for investors to determine the minimum capital required to protect themselves against risk. In the context of the BRVM, the banking sector, insurance companies and institutional investors play a major role in market animation (Essingone and Diallo, 2019). It is therefore entirely legitimate to refer to Basel regulations to define a portfolio risk management strategy in the WAEMU zone.

The method for carrying out backtesting consists first of all in fixing the period of time over which the test is carried out. It is then necessary to record the $\mathrm{VaR}$ and daily profits and losses throughout the period and compare the values obtained day by day. The number of exceptions or violations is then recorded: i.e. the number of times the actual loss exceeds the estimated VaR. The number of exceptions throughout the test period reveals the degree of relevance used to calculate the $\mathrm{VaR}$, and subsequently presents a relevant criterion for judging the quality of the approach used and its appropriateness for the portfolio subject to estimation. Table 7 shows the number of exceptions found in the VaR calculated on 250 observations in our sample and the corresponding capital requirement.

Table 7. Results of the Basel Accord test

\begin{tabular}{cccccc}
\hline Confidence level & Observ & VaR & $\begin{array}{c}\text { Number of } \\
\text { exceptions }\end{array}$ & Zone & Capital required \\
\hline $95 \%$ & 250 & 30.931 & 13 & Red & 123.723 \\
$99 \%$ & 250 & 69.193 & 3 & Green & 207.578 \\
$99.5 \%$ & 250 & 85.709 & 3 & Green & 257.127 \\
$99.9 \%$ & 250 & 124.147 & 1 & Green & 372.442 \\
$99.99 \%$ & 250 & 179.356 & 0 & Green & 538.068 \\
\hline
\end{tabular}

Source: author

According to the Internal Model approach, the regulators act according to the zone in which the investor is positioned: if the investor is in the green zone, there is no penalty under the Basel Committee's guidelines, and the level of capital he must hold is three times the VaR. For example, for a confidence level of $99.9 \%$, the maximum daily loss that the investor could bear is $124.147 \mathrm{XOF}$. In this specific case, he would have to provide a minimum capital of $372.442 \mathrm{XOF}$ to protect himself against this risk on the BRVM market.

On the other hand, if the investor is in the red zone, he is penalised. This is the case for a confidence level of $95 \%$ with 13 exceptions. The required level of equity then becomes 4 times the VaR. In other words, for a maximum daily loss of $30.930 \mathrm{XOF}$, the investor would have to provide himself with capital of $123.723 \mathrm{XOF}$ to guarantee his risk.

\subsection{The Kupiec Test}

The kupiec test is used to validate or reject the VaR model. it is compared to the $\chi^{2}$ critical value of 3.84. By calculating the statistics for the portfolio at different confidence levels, we obtain the results shown in Table 8 below. 
Table 8. Results of the rejection probability test

\begin{tabular}{cccccccc}
\hline $\begin{array}{c}\text { Confidence } \\
\text { level }\end{array}$ & $\begin{array}{c}\text { Critical } \\
\text { value }\end{array}$ & Observ. & Test & Result & Observ. & Test & Test Result \\
\hline $95 \%$ & 3.84 & 250 & 0.021 & Accept & 500 & 0 & Accept \\
$99 \%$ & 3.84 & 250 & 0.095 & Accept & 500 & 0 & Accept \\
$99.5 \%$ & 3.84 & 250 & 1.765 & Accept & 500 & 0.094 & Accept \\
$99.9 \%$ & 3.84 & 250 & 1.275 & Accept & 500 & 0.387 & Accept \\
\hline
\end{tabular}

Source: author

We note that the tests confirm the validation of VaR for all the levels of confidence desired by the investor in the BRVM market. However, at the $99.99 \%$ threshold, the test is not specified because the estimated violation on the corresponding VaR is zero. These results confirm the Basel accords, which define the default rate within a well-defined framework. Consequently, the portfolio is well valued, which allows us to say that these results are reliable.

\subsection{Discussion}

VaR was developed to measure the market risk of the portfolio under stable market conditions. However, this method may not work well in conditions where the financial market is going through a period of crisis characterised by high volatility or changes in asset correlations. As pointed out by the Basel Committee (1996), the market is subject to major changes when the economy experiences major economic shocks resulting in potentially dramatic portfolio losses.

The observation period of our study is particular, at least towards the end of 2019. Indeed, in a context of COVID 19, the BRVM market is experiencing a significant drop in activity, causing high volatility and exceptional portfolio losses for the investor. Given these circumstances, it makes perfect sense to apply the rules that allow this situation of financial stress to be captured.

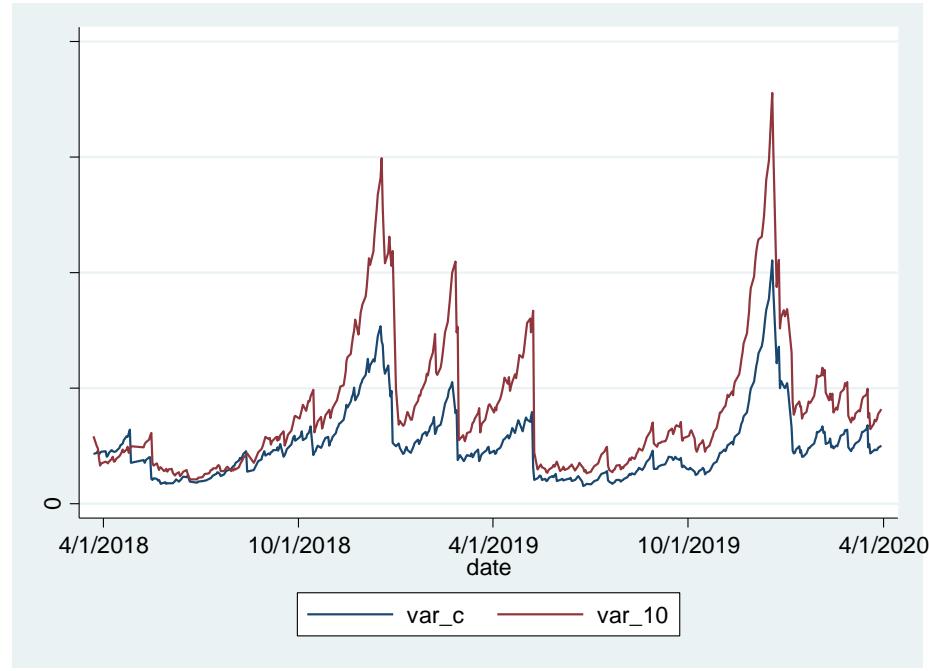

Figure 4. Changes in BRVM volatility

Source: author

To take a closer look at the number of exceptions observed over the period of our study, the portfolio volatility shown in Figure 4 helps us to better understand this problem. A remarkable increase in market volatility can be observed starting in October 2018. At certain times, most notably in October 2019, this increase is greater, characterized by a higher peak. In a situation such as these, it is obvious that the VaRs estimated on the basis of the historical simulation model appear to be too low because the "true" volatility is higher than the volatility of this model.

The results of the backtesting of the equity portfolio illustrate this problem perfectly well. We therefore confirm that VaR only works under normal market conditions. However, this should not be taken to imply that the risk management model would perform better in other circumstances, as we have no way to prove it. However, we can say that backtesting in a stable market environment would produce better results.

Therefore, it should be noted that VaR does not clearly capture portfolio risk in the event that the financial market presents exceptional circumstances. However, there are some general issues that deserve our attention. Portfolio risk management using the $\mathrm{VaR}$ method does not adequately describe the existing risk in the context of a financial crisis. It 
can be said that, at least to some extent, risk management models are not as robust as they appear to be. Some work has shown risk management limits based on the VaR method. For example, (Beder, 1995) found that VaR estimates differed significantly across eight different calculation methods applied to three portfolios. (Berkowicz and O'Brien, 2002) studied the VaR models of six financial institutions and concluded that the models were too conservative and did not accurately capture changes in volatility. These results indicate that actual VaR models are often inaccurate. In addition, empirical tests proving the performance of $\mathrm{VaR}$ models under exceptional market conditions are somewhat limited at this time. Therefore, the whole issue is about the accuracy of VaR models in circumstances of financial stress and may be a hotly debated issue for the future.

The aim of our study is not to question the validity of VaR as a risk measurement method, but it does become a subject of great interest when we look at the results of backetesting here and consider the current financial environment. For us, it is a matter of discussing the attractiveness of the BRVM market through the use of the VaR method and the results of the corresponding backtesting. Indeed, on an empirical level, this approach would allow a good number of investors to quantify the risk and make a judgement on the opportunity that this market can offer in terms of investment. They will then be able to assess their satisfaction in terms of the return generated by the asset portfolio. This method would also help to overcome the shortcomings of traditional theories in estimating return relative to risk. Indeed, if one refers to the theory of expected utility (Von Neumann and Morgenstern, 1947), the investor should base his choice between several alternatives on the basis of maximising the expected utility of a set of results, weighted by their probability of occurrence. The difficulty then lies in estimating this probability and coding the alternatives that are likely to provide a poor representation of the relationship between risk and return.

\section{Conclusion}

VaR has become one of the most widely used methods for measuring market risk. Each VaR model uses historical market data to predict future portfolio performance. In addition, the models are based on approximations and assumptions that are not necessarily valid in all situations. As the methods are far from perfect, there is good reason to question the accuracy of the estimated VaR levels.

The theoretical part of this paper has exposed the different approaches to VaR calculation and its limitations. The turbulent context characterised by the COVID pandemic19 and the high volatility of the market motivated the choice of the extreme VaR method. The results of backtesting enabled us to determine the different VaRs and the corresponding capital requirements.

However, it would be more interesting to carry out a study on the level of investor confidence before determining the $\mathrm{VaR}$ and the corresponding capital requirement. Theories describing individual behaviour such as rank dependent utility models (Quiggin, 1982), perspective theory (Kahneman and Tversky, 1979) or, more recently, the theory of optimal beliefs (Brunnermeier and Parker, 2005), could help to determine this level of confidence.

\section{References}

Basle Committee of Banking Supervision. (1996). Supervisory Framework For The Use of "Backtesting" in Conjunction With The Internal Models Approach to Market Risk Capital Requirements. Available at www.bis.org.

Beder, T. S. (1995). VaR: Seductive but Dangerous. Financial Analysts Journal, 51(5), 12-24. https://doi.org/10.2469/faj.v51.n5.1932

Berkowitz, J., \& O’Brien, J. (2002). How Accurate are Value-at-Risk Models at Commercial Banks? Journal of Finance, 5, 2002. https://doi.org/10.2139/ssrn.278547

Black \& Sholes. (1973). The Pricing of Option and Corporate Liabilities. Journal of Political Economy, 81, 637-659. https://doi.org/10.1086/260062

Brunnermeier, M. K., \& Parker, J. A. (2005). Optimal Expectations. American Economic Review, 95(4), 1092-1118. https://doi.org/10.1257/0002828054825493

Campbell, S. (2005). A Review of Backtesting and Backtesting Procedure, Finance and Economics Discussion Series, Divisions of Research \& Statistics and Monetary Affairs. Federal Reserve Board, Washington D.C. https://doi.org/10.17016/FEDS.2005.21

Dowd, K. (1998). Beyond Value at Risk, The New Science of Risk Management. John Wiley \& Sons, England.

Duménil, G., \& Lévy, D. (2002). The Profit rate: Where and How Much Did it Fall ? Did it Recover? Review of Radical Political Economy, 34, 437- 461. https://doi.org/10.1177/048661340203400403

Elisabeta, J. (2002). Statistica, Editi a III-a, Economica, ISBN 590-666-X.

Fermanian, S. (2003). Nonparametric Estimation of Copulas for Time Series. SSRN Electronic Journal, 5(4). https://doi.org/10.21314/JOR.2003.082 
Field, J. (2003). Social Capital, Routledge, 165 pages.

Figlewski, S. (1994). Forecasting Volatility Using Historical Data. New York University, Working Paper 13.

Gnedenko, B. V. (1943). Sur la Distribution Limite du Terme Maximum d'une Série Aléatoire. Annals of Mathematics, 44, 423-453. https://doi.org/10.2307/1968974

Hearn, B. L; Piesse, J. (2008). Market Liquidity and Stock Size Premia in Emerging Financial Markets: The Implications for Foreign Investment, SSRN. https://doi.org/10.2139/ssrn.1303619

Hull, J., \& White, A. (2017). Optimal Delta Hedging for Options. Journal of Banking and Finance, 82, 180-190.

Essingone, H. N., \& Diallo, M. S. (2019). Risk and Return: The Case of Securities Listed on The West African Economic and Monetary Union Regional Exchange of Securities (BRVM). Applied Economics and Finance, 6, 97-108. https://doi.org/10.11114/aef.v6i1.3778

Jorion, P. (2001). Value at Risk, The New Benchmark for Managing Financial Risk (2nd ed.). McGraw-Hill, United States.

JP Morgan (1997). Creditmetrics-Technical Document. JP Morgan, New York.

Kahneman and Tversky. (1979). Prospect Theory: An Analysis of Decision Under risk. Econometrica, 47(2), 263-291 (March 1979). https://doi.org/10.2307/1914185

Kupiec, P. (1995). Techniques for Verifying the Accuracy of Risk Management Models. Journal of Derivatives, 3, 73-84. https://doi.org/10.3905/jod.1995.407942

Lavelle, K. C. (2001). The Politics of Equity Finance in Emerging Markets. Oxford University Press.

Linsmeier, J., \& Pearson, N. D. (1996). Risk Measurement: An Introduction to Value at Risk, Working Paper 96-04. University of Illinois at Urbana-Champaign.

Lintner, J. (1965). The Valuation of Risk Assets and The Selection of Risky Investments in Stock Portfolios and Capital Budgets. Review of Economics and Statistics, 47, 13-37. https://doi.org/10.2307/1924119

Lucas, A. (1997). An Evaluation of the Basle Guidelines for Backtesting Internal Risk Management Models of Banks, VU Research Memorandum, Free University Amsterdam.

Markowitz, H. (1952). Portfolio selection. Journal of Finance 7, 77-91. https://doi.org/10.1111/j.1540-6261.1952.tb01525.x

Merton, R. C. (1974). On The Pricing of Corporate Debt: the Risk Structure of Interest Rates. Journal of Finance, 29, 449-470. https://doi.org/10.1111/j.1540-6261.1974.tb03058.x

Mossin, J. (1969). Security Pricing and Investment Criteria in Competitive Markets. American Economic Review, 59, 749-756.

Quiggin, J. (1982). A Theory Of Anticipated Utility. Journal Of Economic Behavior and Organization, 3(4), 323-343. https://doi.org/10.1016/0167-2681(82)90008-7

Sharpe, W. (1964). Capital Asset Prices : A Theory of Capital Market Equilibrium Under Conditions of Risk. Journal of Finance, 19, 425-442. https://doi.org/10.1111/j.1540-6261.1964.tb02865.x

Smith, S., \& Wakeman. (1990). The Evolving Market for Swaps, in the Handbook of Currency and Interest Rate Risk Management, ed. Schwartz. New York: New York Institute of Finance Chap. 6.

Treynor, J. (1965). How To Rate Management of Investment Funds. Harvard Business Review, 21, 63-75.

Treynor, J. L. (1962). Toward a Theory of Market Value of Risky Assets. Unpublished manuscript. Rough Draft"dated by Mr. Treynor to the fall of 1962.A.

Tsai, K. T. (2004). Risk Management Via Value at Risk. ICSA Bulletin, January 2004.

Vlaar, P. J. G. (1998). Value at Risk models for Dutch bond portfolios. DNB staff reports no 21, De Nederlansche Bank, Amsterdam.

Von Neumann, J., \& Morgenstern, O. (1947). The Theory of Games and Economic Behavior (2nd ed). Princeton, N.J : Princeton University Press. 


\section{Appendices}

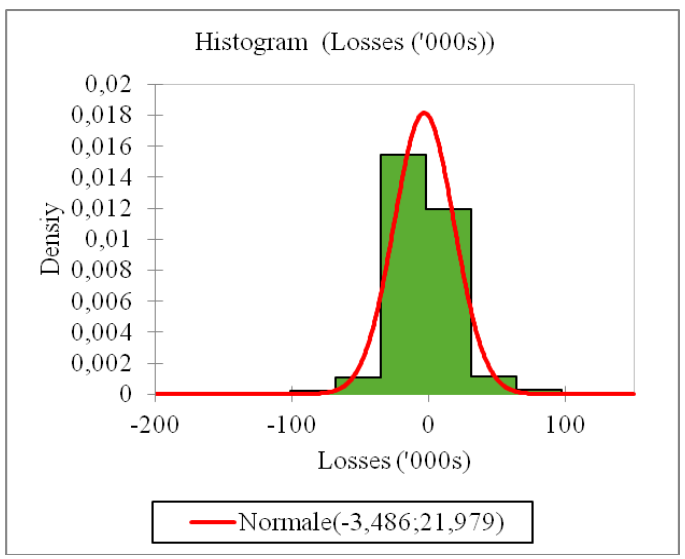

Source: author

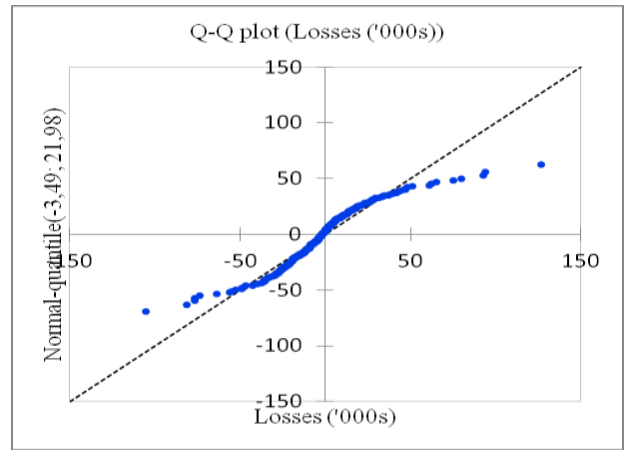

Source: author

Table 9. Correlation of market indexes

\begin{tabular}{lll}
\hline & brvmc & brvm10 \\
\hline Brvmc & 1.000 & \\
brvm 10 & 0.991 & 1.000 \\
\hline
\end{tabular}

Table: List of BRVM companies

\begin{tabular}{|c|c|c|c|c|c|c|c|}
\hline \multicolumn{8}{|c|}{ List of companies making up the BRVMC from 23 March 2018 to 31 March 2020} \\
\hline Industry & & $\begin{array}{l}\text { Public } \\
\text { services }\end{array}$ & Finance & Transport & Agriculture & Distribution & Others \\
\hline $\begin{array}{l}\text { SICABLE CI } \\
\text { CI } \\
\text { BLOHORN CI } \\
\text { NEI CI } \\
\text { CI } \\
\text { SAEC CI } \\
\text { CI } \\
\text { SAGECO CI } \\
\text { CI } \\
\text { SOLIBRA CI } \\
\text { CI } \\
\text { SITAB CI } \\
\text { UNILEVER CI }\end{array}$ & $\begin{array}{r}\text { CEDA } \\
\text { FILTISAC CI } \\
\text { NESTLE } \\
\text { SIEM } \\
\text { SIVOA } \\
\text { SMB } \\
\text { TRITURAF CI } \\
\text { UNIWAX CI }\end{array}$ & $\begin{array}{l}\text { CIE CI } \\
\text { ONTBF } \\
\text { SODECI } \\
\text { SONATEL }\end{array}$ & $\begin{array}{l}\text { BICICI CI } \\
\text { BOAC } \\
\text { BOA BN } \\
\text { BOA BF } \\
\text { BOAN } \\
\text { ETIT } \\
\text { SAFCA CI } \\
\text { SGBCI }\end{array}$ & $\begin{array}{l}\text { SAGA CI } \\
\text { SDV CI } \\
\text { SIVOM }\end{array}$ & $\begin{array}{l}\text { PALMCI } \\
\text { PHCI } \\
\text { SICOR CI } \\
\text { SOGB CI } \\
\text { SAPH CI }\end{array}$ & $\begin{array}{l}\text { ABIDJAN CAT } \\
\text { BERNABE CI } \\
\text { CFAO CI } \\
\text { ELF CI } \\
\text { PEYRISSAC CI } \\
\text { SHELL CI } \\
\text { SARI CI } \\
\text { SOCIMAT CI } \\
\text { TOTAL CI }\end{array}$ & SETAO \\
\hline
\end{tabular}

\section{Copyrights}

Copyright for this article is retained by the author(s), with first publication rights granted to the journal.

This is an open-access article distributed under the terms and conditions of the Creative Commons Attribution license which permits unrestricted use, distribution, and reproduction in any medium, provided the original work is properly cited. 